\title{
Is It Time To Flip
}

A.Z. Elsamanoudy ${ }^{(1)}$ and R.M. Mostafa ${ }^{(2)}$

(1) Prof. of Medical Biochemistry and Molecular Biology

Faculty of Medicine, Mansoura University, Egypt

(2) Prof of Physiology and Head of the department

Faculty of Medicine, Benha University, Egypt

Corresponding author :prof. Randa M Mostafa

E-mail address: Randa.Moustafa@fmed.bu.edu.eg

Tel: +201026266125

Fax: +2084636583

Since Salman Khan, The creator of Khan Academy showed the power of interactive excercises and called for all teachers to consider flipping the traditional classroom, flipping classrooms are attracting an increasing amount of medical educators attenstion (Khan,S. 2011)

\section{What is flipped classroom?}

Flipping the classroom is a paradigmatic switch in education. It represents a shift from teacher-centered in the form of lecturing to learning-centered instructional strategies with active student engagement.

The flipped classroom (also called reverse, inverse, or backward classroom). It is the pedagogical maneuver in which basic concepts and objectives are provided to students for pre-class learning. Then, the class time can apply and build upon those basic concepts (Bergmann, Sams 2012; Persky et al., 2017).

Flipped classroom model has been suited for medical education; the learner is assigned content to review prior to the teaching session via assignments and activities. Pre-class assignments create a framework of core knowledge, and the active learning exercise helps to apply the knowledge in an interactive, compelling and engaging format (Prober C, Khan 2013). Class time is used for the application of knowledge in an active learning session (Thompson 2011). This teaching approach and procedure employ active learning process and consequently create positive learning outcomes (Courch, Mazur 2001; Morgan et al., 2015).

To apply a properly structured and effective flipped classroom, the following rules and steps should be followed strictly. Course alignment with design process should be ensured to verify that the content, materials, required activities, and even the method of assessments are optimally positioned to meet student learning objectives goals( Abrami et al., 2008). Course objectives should meet students expectations.Objectives need to be high but at the same time should be achievable.The objectives should be specific, measurable, actionable, relevant and timely structured (Emery et al., 2014).

In the flipped classroom, students must obtain foundational material outside of 
class, prepared for in-class activities. This is referred as self-paced learning, selfdirected learning or, self-regulated learning that could be defined as learners are permitted to decide to select the method, depth, and way to deliver the information they want to experience (Rehder, Hoffman 2005). After that, class time is the time used to reinforce and extend learning mainly through an application and problem-solving to verify the effectiveness of this active learning process.via higher-order thinking skills, collaborative skills, and self-awareness (Freeman et al., 2014).

Pre-class and in-class activities, discussion and researches should be focused and not to be the end. It should be after-class work to be sure that course objectives are achieved, the self-learning process is verified and students intrinsic motivation is promoted (Persky et al., 2017).

Finally, assessment strategies with pre and in-class learning objectives and activities are critical and mandatory for maximum student outcomes achievement (Hodges et al., 2015). Each stage of the Flipped class has its own assessment tool; a variety of methods for assessment of pre-class activity include: quizzes are given at the beginning of class, group learning activities, problem-solving, case discussions(McLaughlin et al., 2014). Anecdotal evidence and discussions of flipped classrooms usually focus on the off-loaded content stage. However, inclass activities are actually the most important instructional component.
Classroom time is valuable and should make the best use of instructor knowledge, experience, and abilities to assist students in learning how to think. So, synchronous oral discussion and exam are strictly important for the assessment of this stage (Rotellar C, Cain 2016).

In general speaking, the flipped classroom could stimulate students' learning motivation, improve performance regarding assessment and exam. Moreover, it may help to enhance critical thinking as well as communication skills (Tang et al., 2017).In addition to the more interactivity, active participation, more easy access to experts, and retention of material, Faculty could get better ability to assess students' critical thinking and provide rapid constructive feedback(Young et al., 2014).

Some limitation could be found in the flipped classroom educational method such as students' actual total time engagement during pre-work activity could not be evaluated actually (Novak 2011). The variability in flipped classroom designs could be considered as another limitation as for the implementation and in-class activities show great variation (O'Flaherty, Phillips 2015). Also, the type, of course, could be a limitation of the flipped class application as reported by a meta-analysis presented recently by Gillette et al., (2018).

On conclusion, flipping the classroom is a challenge, requires more work and careful planning to adjust some of the students' out of classroom study time. Nevertheless, the energy and interactive discussion that brings to the classroom makes it work. 


\section{REFERENCES :}

[1] S. Khan, in TED Talks (2011), pp. 20-27 (http://www.ted.com/talks/salman_khan_ let_s_use video to reinvent education.h $\underline{\mathrm{tml}}$

[2] Thompson C. How Khan Academy is changing the rules of education. Wired Posted 15 July 2011.Available at http://www.wired.com/magazine/2011/07 /ff_khan/.Accessed on 26 March 2014.

[3] Courch CH , Mazur E . Peer instruction:Ten years of experience and results . Am J Physics 2001; 69 :970 977 .

[4] Prober C , Khan S . Medical Education Reimagined: A Call to Action . Acad Med 2013; $88: 1407$ - 1410 .

[5] Tune JD , Sturek M , Basile DP . Flipped classroom model improves graduate student performance in cardiovascular, respiratory and renal physiology . Adv Physiol Educ 2013 ; 37 : 316-320 .

[6] Morgan, Helen; McLean, Karen; Chapman, Chris; Fitzgerald, James; Yousuf, Aisha; Hammoud, Maya (2015). "The flipped classroom for medical students." The Clinical Teacher (3): 155160.

[7] Bergmann J, Sams A. Flip Your Classroom: Reach Every Student in Every Class Every Day. Eugene, OR: International Society for Technology in Education; 2012.

[8] Persky, Adam M and Jacqueline E McLaughlin. "The Flipped Classroom From Theory to Practice in Health Professional Education" American journal of pharmaceutical education vol. 81,6 (2017): 118.

[9] Abrami PC, Bernard RM, Borokhovski E, et al. Instructional interventions affecting critical thinking skills and dispositions: a stage 1 meta-analysis. Rev Educ Res. 2008;78(4):1102-1134.

[10] Emery M, Bush C, Bounds R, Gillett B, Santen S, Aghera A. Enhancing learning with simulation: setting "SMART" learning goals during debriefing improves self-directed learning. Annal Emerg Med. 2014;64(4):S116.

[11] Rehder B, Hoffman AB. Eyetracking and selective attention in category learning. Cogn Psychol. 2005;51(1):1-41.

[12] Freeman S, Eddy SL, McDonough M, et al. Active learning increases student performance in science, engineering, and mathematics. Proc Nat Acad Sci. 2014;111(23):8410-8415.

[13] Hodges LC, Anderson EC, Carpenter TS, et al. Using reading quizzes in STEM classes - the what, why, and how. J College Sci Teach. 2015;45(1):49.

[14] Tang, F., Chen, C., Zhu, Y., Zuo, C., Zhong, Y., Wang, N., Zhou, L., Zou, Y., ... Liang, D. (2017). Comparison between flipped classroom and lecturebased classroom in ophthalmology clerkship. Medical education online, 22(1), 1395679.

[15] Young TP, Bailey CJ, Guptill M, Thorp AW, Thomas TL. The flipped classroom: a modality for mixed asynchronous and synchronous learning in a residency program. West J Emerg Med. 2014;15(7):938-44.

[16] Novak GM. Just-in-time teaching. N Direct Teach Learn 2011: 63-73,2011.

[17] O'Flaherty J, Phillips C. The use of flipped classrooms in higher education: a scoping review. Internet Higher Educ 25: 85-95, 2015. 
[18] Gillette C, Rudolph M, Kimble C, Rockich-Winston N, Smith L, BroedelZaugg K. A Meta-Analysis of Outcomes Comparing Flipped Classroom and Lecture. Am J Pharm Educ. 2018;82(5):6898.

[20] McLaughlin JE, Roth MT, Glatt DM, et al. The flipped classroom: a course redesign to foster learning and engagement in a health professions school. Acad Med. 2014;89(2):236243.
[19] Rotellar C, Cain J. Research, Perspectives, and Recommendations on Implementing the Flipped Classroom. Am J Pharm Educ. 2016;80(2):34.

[21] Ramírez, D., Hinojosa, C., and Rodríguez, F. (2014). Advantages and disadvantages of flipped classroom: Stem students' perception. In 7th International Conference of Education, Research and Innovation, pages 121127, Seville, Spain. 